\title{
A brief intervention targeting primary-care physician prescribing of pharmacotherapies for alcohol dependence: can it impact prescribing behavior and reduce hospital inpatient admissions?
}

\author{
Anthony Shakeshaft \\ From International Network on Brief Interventions for Alcohol Problems (INEBRIA) Meeting 2011 \\ Boston, MA, USA. 21-23 September 2011
}

Increasing the use of pharmacotherapies for alcohol dependence has the potential to improve patient outcomes and reduce health-care costs by reducing hospital admissions. This randomized controlled trial (RCT) evaluated the cost-effectiveness of tailored mailed feedback on general practitioner (GP) prescribing for alcohol dependence and alcohol-related hospital admissions. General practitioners $(\mathrm{N}=115)$ in 10 communities randomized to the experimental arm of the Alcohol Action in Rural Communities (AARC) project received tailored mailed feedback on their prescribing of acamprosate and naltrexone. Segmented regression analysis examined the impact of the intervention relative to GPs' prescribing and inpatient hospital admissions for alcohol dependence in those communities. Incremental cost-effectiveness ratios were estimated to compare costs per additional prescription written and costs per inpatient admission averted. Trend analysis showed GPs significantly increased their prescribing of acamprosate $(\beta=0.24 ; 95 \%$ confidence interval $[\mathrm{CI}]$, 0.13-0.35) and significantly decreased their prescribing of naltrexone ( $\beta=0.12$; 95\% CI, 0.13-0.35). Rates of alcoholrelated inpatient admissions for alcohol dependence decreased significantly in the experimental group compared with the control group ( $(=0.98$; 95\% CI, 1.80-0.16). Similar to evidence showing SBI can improve patient outcomes, this study showed mailed tailored feedback to GPs achieved cost-effective increases in their prescribing of acamprosate, with a subsequent and plausibly causal reduction in inpatient hospital admissions for alcohol

National Drug and Alcohol Research Center, University of New South Wales, Sydney, Australia

(c) 2012 Shakeshaft; licensee BioMed Central Ltd. This is an Open Access article distributed under the terms of the Creative Commons Attribution License (http://creativecommons.org/licenses/by/2.0), which permits unrestricted use, distribution, and reproduction in any medium, provided the original work is properly cited. dependence. Demonstrating the capacity of brief intervention in primary-care settings to reduce demand for tertiary care services appears to be a promising direction for the SBI field. A large-scale RCT of the cost benefit of tailored feedback to GPs appears warranted.

Published: 9 October 2012

doi:10.1186/1940-0640-7-S1-A75 physician prescribing of pharmacotherapies for alcohol dependence: can it impact prescribing behavior and reduce hospital inpatient admissions? Addiction Science \& Clinical Practice 2012 7(Suppl 1):A75.

Submit your next manuscript to BioMed Central and take full advantage of:

- Convenient online submission

- Thorough peer review

- No space constraints or color figure charges

- Immediate publication on acceptance

- Research which is freely available for redistribution
Cite this article as: Shakeshaft: A brief intervention targeting primary-care

- Inclusion in PubMed, CAS, Scopus and Google Scholar \\ C Biomed Central}

